\title{
Medicinal plants for kidney pain: An ethnobotanical study on Shahrekord city, West of Iran
}

\author{
Abdolreza Reza Kheirollahi ${ }^{1}$, Leila Mahmoodnia ${ }^{2}$, Elham Khodadustan ${ }^{2}$, Hamidreza Kazemeini ${ }^{3}$, \\ Afshin Hasanvand ${ }^{4} \&$ Masoom Hatamikia $^{4^{*}}$
}

${ }^{1}$ Department of Internal Medicine, School of Medicine, Lorestan University of Medical Sciences, Khorramabad, Iran

${ }^{2}$ Department of Internal Medicine, School of Medicine, Shahrekord University of Medical Sciences, Shahrekord, Iran

${ }^{3}$ Department of Food Hygiene, Faculty of Veterinary Medicine, Amol University of Special Modern Technologies, Amol, Iran

${ }^{4}$ Deputy for Food and Drug, Lorestan University of Medical Sciences, Khorramabad, Iran

\section{Article history}

Received: 16 June 2019

Accepted: 09 July 2019

Published: 20 July 2019

\section{Publisher}

Horizon e-Publishing Group

\section{*Correspondence}

Masoom Hatamikia

凶mahatamikia@yahoo.com

\begin{abstract}
Kidney problems such as kidney stones, pyelonephritis, nephropathy, diabetes, hypertension and other kidney complications can cause kidney pain. In general, opioid and non-opioid systemic analgesics are used to control pain that have many side effects such as nausea, vomiting, sedation, and respiratory depression. Studies on plants that can be useful in the treatment of kidney diseases such as kidney pain are difficult and little research has been done in this regard. Therefore, in this ethnobotanical study, plant antioxidants and medicinal plants affecting kidney pain were identified. For this purpose, a questionnaire was used to identify and obtain indigenous information and knowledge of traditional therapists in Shahrekord regarding the treatment of kidney pain. This ethnobotanical study was conducted from 21 April, 2016 to 19 February, 2017 in 29 traditional therapists of the region under purpose. Finally, the data drawn from the questionnaires were analyzed using the Excel software. In this study, the frequency of plant use was also calculated. The results of this study showed that 16 species of medicinal plants from 11 plant families in this region are used to cure kidney pain. The most frequently used are for anti-kidney pain was Alhagi maurorum (79\%) followed by Tribulus terrestris (70\%). Besides, the Asteraceae (5 plant species) was the largest family of medicinal plants with anti-kidney pain effect, and the flower (32\%) was the most frequently used plant organ for anti-kidney pain property.
\end{abstract}

Keywords: ethnobotany; medicinal plants; urinary tract; kidney pain; Shahrekord; Iran

Citation: Kheirollahi AR, Mahmoodnia L, Khodadustan E, Kazemeini H, Hasanvand A, Hatamikia M. Medicinal plants for kidney pain: An ethnobotanical study on Shahrekord city, West of Iran. Plant Science Today 2019; 6(3):328-332. https://doi.org/10.14719/pst.2019.6.3.592

Copyright: (C) Kheirollahi et al (2019). This is an open-access article distributed under the terms of the Creative Commons Attribution License, which permits unrestricted use, distribution, and reproduction in any medium, provided the original author and source are credited (https://creativecommons.org/licenses/by/4.0/).

Indexing: Plant Science Today is covered by Scopus,Web of Science, BIOSIS Previews, ESCI, CAS, AGRIS, CABI, Google Scholar, etc. Full list at http://www.plantsciencetoday.online

\section{Introduction}

Kidney problems pyelonephritis, such as kidney stones, nephropathy, diabetes, hypertension and other kidney complications can cause kidney pain (1-3). If these diseases and complications are not treated, they can lead to serious damage even life-threatening complications and illnesses including kidney failure (4-7). The causes of kidney pain include atherosclerosis or hardening of the renal arteries due to blood clotting 
or ischemia, kidney bleeding, horseshoe kidney, hydronephrosis, kidney tumors, urinary tract infection, urinary tract obstruction, etc (4-7). If the pain is severe, certain analgesics can be used to alleviate the pain until undergoing proper treatment $(8,9)$. In general, opioid and non-opioid treatment of kidney pain. This ethnobotanical study was conducted from 21 April, 2016 to 19 February, 2017 in 29 traditional therapists of the region under study (Fig. 1. - Shahrekord map). First, a questionnaire was prepared and then filled out through face-to-face interview. The

Table 1. Scientific name, family, Persian name, used organ(s) and frequency of use of medicinal plants used as anti-kidney pain agents in Shahrekord.

\begin{tabular}{|c|c|c|c|c|c|c|}
\hline Sl. No. & Scientific name & family & Local name & $\begin{array}{l}\text { Frequency } \\
\text { of use }\end{array}$ & Organs used & Treatment \\
\hline 1 & Eugenia caryophyllata & Myrtaceae & Mikhak & $44 \%$ & Flower, stem & Kidney pain \\
\hline 2 & Tribulus terrestris L. & Zygophyllaceae & Kharkhasak & $70 \%$ & Aerial organs & Kidney pain \\
\hline 3 & Alhagi maurorum Medik. & Fabaceae & Kharshotor & $79 \%$ & Aerial organs & Kidney pain \\
\hline 4 & Hypericum scabrum L. & Hypericaceae & Gole raei & $3 \%$ & Flower, stem & Kidney pain \\
\hline 5 & Echinophora platyloba DC. & Apiaceae & Khosharizeh & $13 \%$ & Aerial organs & Kidney pain \\
\hline 6 & Hyoscyamus kotschyanus Pojark. & Solanaceae & Bang daneh & $2 \%$ & Seed, leaf & Kidney pain \\
\hline 7 & Papaver rhoeas L. & Papaveraceae & Gole shaghaiegh & $3 \%$ & Flower & Kidney pain \\
\hline 8 & Zingiber officinale Roscoe & Zingiberaceae & Zanjabil & $2 \%$ & Root, stem & Kidney pain \\
\hline 9 & Centaurea cyanus L. & Asteraceae & Gole gandom & $3 \%$ & $\begin{array}{l}\text { Stem, leaf, } \\
\text { flower }\end{array}$ & Kidney pain \\
\hline 10 & Tripleurospermum parviflorum L. & Asteraceae & Babouneh kazeb & $13 \%$ & Flower & Kidney pain \\
\hline 11 & Melissa officinalis L. & Lamiaceae & Badranjbouyeh & $3 \%$ & Aerial organs & Kidney pain \\
\hline 12 & Achillea millefolium $\mathrm{L}$. & Asteraceae & Boumadaran & $3 \%$ & Aerial organs & Kidney pain \\
\hline 13 & Tanacetum polycephalum (L.) Schultz-Bip. & Asteraceae & Mokhalaseh & $3 \%$ & Aerial organs & Kidney pain \\
\hline 14 & Valeriana officinalis L. & Caprifoliaceae & Sonbolatieb & $3 \%$ & Flower, stem & Kidney pain \\
\hline 15 & Thymus vulgaris L. & Lamiaceae & Avishan & $3 \%$ & Leaf, flower & Kidney pain \\
\hline 16 & Hyssopus augustifolius M.B. & Lamiaceae & Zofa & $3 \%$ & $\begin{array}{l}\text { Leaf, stem, } \\
\text { flower }\end{array}$ & Kidney pain \\
\hline
\end{tabular}

systemic analgesics are used to control pain that have many side effects such as nausea, vomiting, sedation, and respiratory depression $(10,11)$. Finding a safe and reliable pharmaceutical source to control pain is therefore a good strategy for managing kidney pain. One of these methods is the use of medicinal plants. Medicinal plants are used in the treatment of diseases of human viscera such as the heart, kidney, liver, digestive system and genitalia, respiratory system and nervous system due to the presence of active antioxidant and medicinal substances (12-18). Studies on plants that can be useful in the treatment of kidney diseases such as kidney pain are difficult and little research has been done in this regard. Medicinal herbs used for kidney pain in different parts of Iran include Achila mellifolium, Berberis vulgaris, Equisetum arvense, Alhagi persarum, Lycium depressum, Allium haemanthoides, Petroselinum crispum, Hyoscyamus orthocarpus, Ceratocephalus falcata, Malva neglecta, and Zizyphus jujube (1927). Therefore, in this ethnobotanical study, plant antioxidants and medicinal plants that are effective on kidney pain were identified.

\section{Materials and Methods}

\section{Data collection procedure}

A questionnaire was used to identify and obtain indigenous information and knowledge of traditional therapists in Shahrekord about the questionnaire included demographic information (location, characteristics of the interviewer, native name and used organ(s) of the plant, and education level). The interviewers referred to the respondents in person and received their pharmaceutical and ethnobotanical information and record it in the questionnaires.

Data were finally analyzed by the Excel software. In this study, the frequency of plant use was calculated by the formula given below (27).

Number of times the plant is used $=$ (Number of people who have mentioned the plant effect divided by total number of people who filled out questionnaires) $\times 100$

\section{Results}

Out of 29 respondents, 8 were female and 21 male. The respondents' education level was from high school diploma to master's degree. The data drawn from the questionnaires were uniformly tabulated. The results of this study showed that 17 species of medicinal plants consisting of Eugenia caryophyllata, Tribulus terrestris, Alhagi maurorum, Hypericum scabrum, Echinophora platyloba, Hyoscyamus kotschyanus, Papaver rhoeas, Zingiber officinale, Centaurea cyanus, Tripleurospermum parviflorum, Melissa officinalis, Achillea millefolium, Tanacetum polycephalum, Valeriana officinalis, Thymus vulgaris and 
Hyssopus augustifolius from 11 plant families in this region are used as anti-kidney pain medicinal plants according to the ethnobotanical knowledge of the region. Additional information on antikidney pain medicinal plants is shown in Table 1.

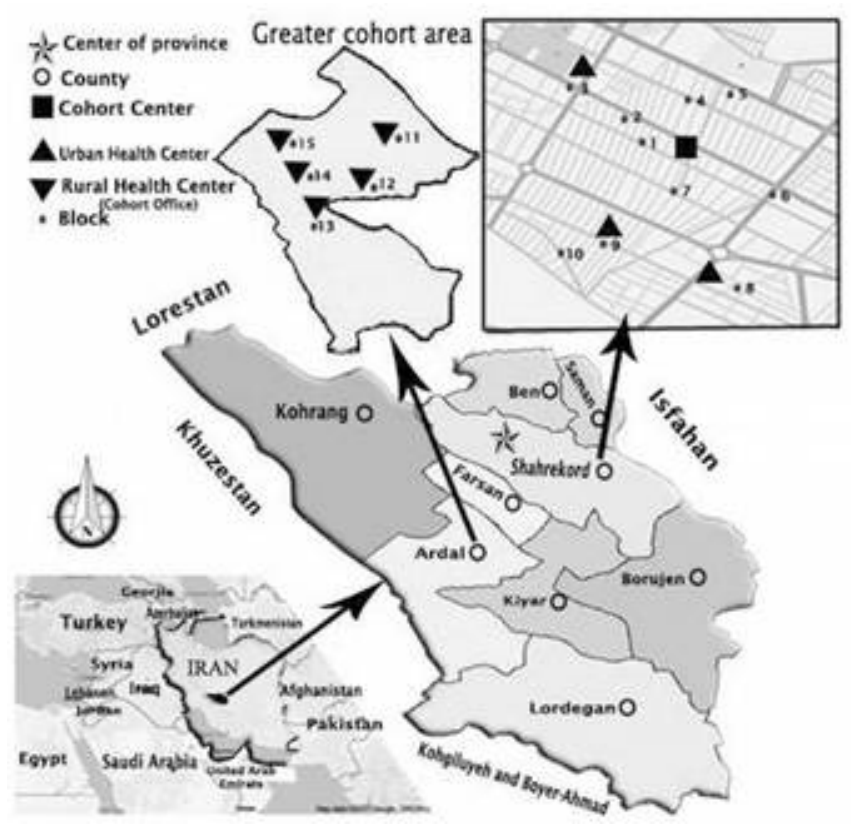

Fig. 1. Shahrekord's area map

As Table 1 shows, the most frequently used plant as anti-kidney pain medicinal plant was Alhagi maurorum (79\%) followed by Tribulus terrestris $70 \%$. Besides, the family Asteraceae (5 plant species) was the largest family of medicinal plants with anti-kidney pain effect, and the flower (32\%) was the most frequently used plant organ for its anti-kidney pain property. Additional information is presented in Table 1 and illustrated in Fig. 2 and Table 2.

Table 2. The distribution of plant families for kidney pain in Shahrekord.

\begin{tabular}{ll}
\hline Family & Number \\
\hline Caprifoliaceae & 1 \\
\hline Lamiaceae & 3 \\
\hline Asteraceae & 5 \\
\hline Zingiberaceae & 1 \\
\hline Papaveraceae & 1 \\
\hline Solanaceae & 1 \\
\hline Myrtaceae & 1 \\
\hline Apiaceae & 1 \\
\hline Hypericaceae & 1 \\
\hline Fabaceae & 1 \\
\hline Zygophyllaceae & 1 \\
\hline
\end{tabular}

\section{Discussion}

According to the ethnobotany of Shahrekord, the medicinal plants such as Eugenia caryophyllata, Tribulus terrestris, Alhagi maurorum, Hypericum scabrum, Echinophora platyloba, Hyoscyamus kotschyanus, Papaver rhoeas, Zingiber officinale, Centaurea cyanus, Tripleurospermum parviflorum, Melissa officinalis Achillea millefolium, Tanacetum polycephalum, Valeriana officinalis, Thymus vulgaris and Hyssopus augustifolius are used to relieve kidney pain. According to traditional medicine in different regions of Iran, various medicinal plants are used to treat kidney pain. In Abadeh, Shiraz (southern Iran), Amygdalus oreintalis and Achila mellifolium are used to treat kidney pain (19). In Arasbaran (north of Iran), the medicinal plants Berberis vulgaris L. and Equisetum arvense (20), in Ilam province (west of Iran), Alhagi persarum and Lycium depressum (21), in Khuzestan province (southwest of Iran), Allium haemanthoides, Petroselinum crispum and Hyoscyamus orthocarpus (22), in Sistan, Malva neglecta and Alhagi persarum (23), in Mobarakeh, Isfahan (central Iran), Petroselinum crispum and Matricaria recutita (24), in Hormozgan province (southern Iran), Tribulus macropterus and Tribulus terresteris (25) and in Hamadan (southwest of Iran), Ceratocephalus falcata (26) are used as a curative for kidney pain. Some medicinal plants in different regions of Iran, including those occurring in the Shahrekord region, have ani-jaundice effects. According to the results of this study and given the emphasis of traditional medicine on the anti-kidney pain effects of medicinal plants, these plants can have a preventive effect against problem, but it is necessary to investigate these effects in clinical and pharmacological studies.

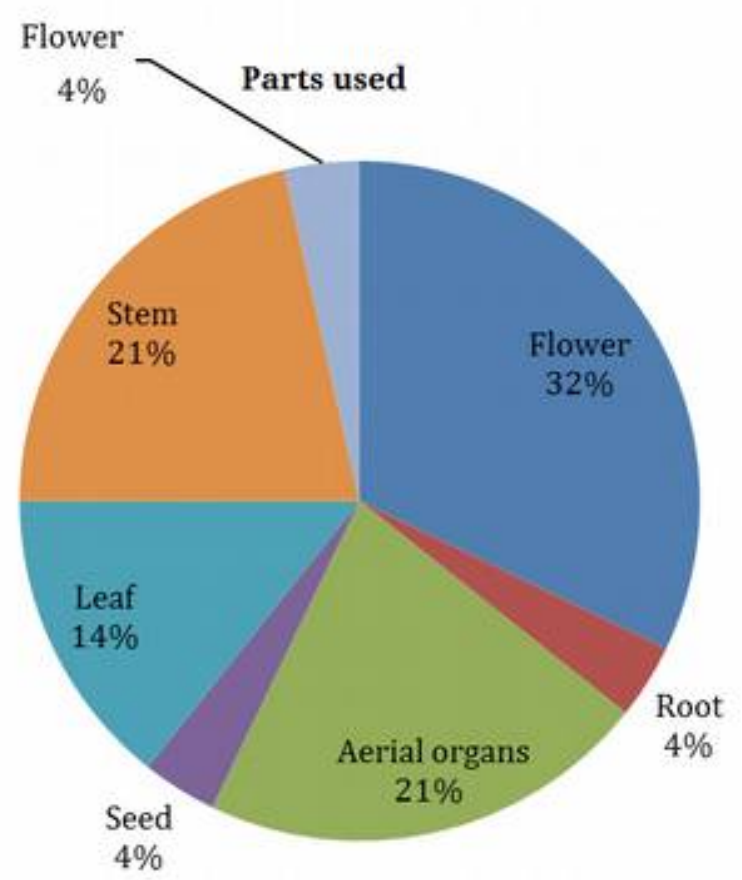

Fig. 2. The percentage of the use of plants organs with antikidney pain property in Shahrekord.

\section{Conclusion}

These plants might be used as alternative or complementary remedies and might be used for preparation of new drugs. 


\section{Acknowledgements}

The authors are grateful to the Shahrekord and Lorestan University of Medical Sciences, Iran for financial assistance.

\section{Authors' contributions}

All the authors contributed equally to the work presented in this paper.

\section{Competing Interests}

The authors declared that they have no conflict of interest.

\section{Appendix 1}

1. Date

2. City/Village

3. Informant name and surname

4. Age

5. Degree of education

6. Family origin

7. Which wild plants do you use to treat the different ailments?

8. How you have learned to traditional information?

9. Which plant parts do you use in traditional information?

10. What is the vernacular name of these plants / part of plants in traditional information?

11. Can you describe the preparation of remedy in detail?

12. When should the medicine be taken and for how long?

13. Internal or external administration?

14. Where does this knowledge arrive from?

\section{References}

1. Kennedy J, Roll JM, Schraudner T, Murphy S, McPherson S. Prevalence of persistent pain in the U.S. Adult population: new data from the 2010 national health interview survey. J Pain. 2014; 15(10): 979-984. https://doi.org/10.1016/j.jpain.2014.05.009

2. Levey AS, Coresh J. Chronic kidney disease. Lancet. 2012; 379(9811): 165-180. $\quad$ https://doi.org/10.1016/S01406736(11)60178-5

3. Coresh J, Selvin E, Stevens LA, et al. Prevalence of chronic kidney disease in the United States. Jama 2007; 298: 2038-2047. https://doi.org/10.1001/jama.298.17.2038

4. Foxman B. Epidemiology of urinary tract infections: incidence, morbidity, and economic costs. Dis Mon 42003; 9: 53-70. https://doi.org/10.1067/mda.2003.7

5. Torres VE, Harris PC, Pirson Y. Autosomal dominant polycystic kidney disease. Lancet. 2007; 369: 1287-1301. https://doi.org/10.1016/S0140-6736(07)60601-1

6. Fauci AS, Kasper DL, Hauser SL, Longo DL, Jameson JL, Loscalzo J. Harrison's internal medicine urinay tract infections pyelorephirhis and prostatis. New York: McGraw Hill; 2008.

7. Mandell G, Bennett J, Dolin R. Principles and practice of infectious diseases. 6th ed. St.Louis: Mosby; 2005.
8. Woolf CJ. Pain: moving from symptom control toward mechanism-specific pharmacologic management. Ann Intern Med 2004; 140: 441-451. https://doi.org/10.7326/0003-4819-140-8-200404200-00010

9. Rang HP, Bevan S, Dray A. Chemical activation of nociceptive peripheral neurons. Br Med Bull 1991; 47: 534538. https://doi.org/10.1093/oxfordjournals.bmb.a072491

10. Goldstein A, Grimault P, Henique A, Keller M, Fortin A, Darai E. Preventing post operative pain by local anesthetic instillation after laparoscopic gynecologic surgery: A placebo controlled comparison of Bupivacaine and Ropivacaine. Anesth Analg 2000; 91: 403-7. https://doi.org/10.1097/00000539-200008000-00032

11. Rana AM, Bhojwani JP, Junejo NN, Das Bhagia S. Tubeless PCNL in supine position: procedure for all seasons? With comprehensive technique. Urology 2008; 71: 581-5. https://doi.org/10.1016/j.urology.2007.10.059

12. Faryadian S, Sydmohammadi A, Khosravi A, Kashiri M, Faryadayn P, Abasi N. Aqueous extract of Echlum amoenum elevate CSF serotonin and dopamine level in depression rat. Biomedical and Pharmacology Journal 2014; 7(1): 137-142.

13. Abbasi N, Azizi Jalilian F, Abdi M, Saifmanesh M. A comparative study of the antimicrobial effect of Scrophularia striata Boiss. Extract and selective antibiotics against Staphylococcus aureus and Pesudomonas aeruginosa. Journal of Medicinal Plants 2007; 6(SUPPL. 1): 10-18+69.

14. Bahmani M, Khaksarian M, Rafieian-Kopaei M, Abbasi N. Overview of the therapeutic effects of Origanum vulgare and Hypericum perforatum based on Iran's ethnopharmacological documents. Journal of Clinical and Diagnostic Research 2018; 12(7): 1-4. https://doi.org/10.7860/JCDR/2018/34177.11728

15. Shokri Z, Khoshbin M, Koohpayeh A, Abbasi N, Bahmani F, Rafieian-Kopaei, M, Beyranvand F. Thyroid diseases: Pathophysiology and new hopes in treatment with medicinal plants and natural antioxidants. International Journal of Green Pharmacy 2018; 12(3): 473-482.

16. Valadi A, Nasri S, Abbasi N, Amin GR. Antinociceptive and anti-inflammatory effects of hydroalchoholic extract of Anethum graveolens L. seed. Journal of Medicinal Plants 2010; 9(34): 124-130.

17. Tajbakhsh M, Karimi A, Tohidpour A, Abbasi N, Fallah F, Akhavan MM. The antimicrobial potential of a new derivative of cathelicidin from Bungarus fasciatus against methicillin-resistant Staphylococcus aureus. Journal of Microbiology 2018; 56(2): 128-137. https://doi.org/10.1007/s12275-018-7444-5

18. Bahmani M, Taherikalani M, Khaksarian M, RafieianKopaei M, Ashrafi B, Nazer M et al., The synergistic effect of hydroalcoholic extracts of Origanum vulgare, Hypericum perforatum and their active components carvacrol and hypericin against Staphylococcus aureus. Future Sci OA. 2019 Jan 31; 5(3): FSO371. https://doi.org/10.4155/fsoa-2018-0096

19. Razmjouei D, Zarei Z, Akbari M. Ethnobotanical study of medicinal plants of Abadeh city in Fars province. Journal Plants Ecophysiology 2015; 7(3): 222-234.

20. Zolfaghari A, Adeli A, Mozafarian V, Babaei S, HabibiBibalan Gh. Identification of medicinal plants and indigenous knowledge of local people Arasbaran. J Med Arum Plants. 2013; 28(3): 534- 550.

21. Ghasemi Pirbalouti A, Momeni M. and Bahmani M. Ethnobotanical study of medicinal plants used by kurd tribe in dehloran and abdanan districts, ilam province Iran. Afr J Tradit Complement Altern Med. 2013; 10(2): 368-385. https://doi.org/10.4314/ajtcam.v10i2.24 
22. Khodayari H, Amani SH, Amiri H. Ethnobotanical study of North east of Khuzistan province. Med Plants Ecophytochemistry J 2013; 8: 2(4): 12-26.

23. Iranmanesh $\mathrm{M}$, Najafi $\mathrm{SH}$, Yosefi M. Studies on Ethnobotany of important medicinal plants in Sistan. J Herbal Drugs 2010; 1(2): 58-65.

24. Shaahin Mardani-Nejhad; Mansoureh Vazirpour. Ethnobotany of medicinal plants by Mobarakeh's people (Isfahan). J Herbal Drugs 2012; 3(2): 111-126.

25. Safa O, Soltanipoor MA, Rastegar S, Kazemi M, Nourbakhsh Dehkordi KH, Ghannadi A. An ethnobotanical survey on hormozgan province, Iran. Avicenna Journal of Phytomedicine 2013; 3(1): 64-81.

26. Naghibi F, Esmaeili S, Malekmohammadi M, Hassanpour A, Mosaddegh M. Ethnobotanical survey of medicinal plants used traditionally in two villages of Hamedan, Iran. Avicenna J Phytomed. 2014; 1(3): 7-14.

27. Saber Abbaszadeh, Hassan Teimouri, Behrouz Farzan Ethno-botanical study of sedative medicinal plants in Shahrekord. Egyp J Vet Sci 2019; 50(2): 99-105. https://doi.org/10.21608/ejvs.2019.12613.1078 